\title{
Magnetically Induced Crystal Alignment of Calcium Hydrogen Phosphate Dihydrate
}

\author{
Takeshi Hagio $^{1}$, Kazushige Yamauchi ${ }^{2} \&$ Kazuhiko Iwai ${ }^{1}$ \\ ${ }^{1}$ Division of Materials Science and Engineering, Hokkaido University, Sapporo, Hokkaido, Japan \\ ${ }^{2}$ Department of Material, Physics and Energy Engineering, Nagoya University, Furo-cho, Chikusa-ku, Nagoya, \\ Japan \\ Correspondence: Takeshi Hagio, Division of Materials Science and Engineering, Hokkaido University, Sapporo, \\ Hokkaido, Japan. E-mail: t-hagio@ec.hokudai.ac.jp
}

Received: January 6, 2014 Accepted: January 27, 2014 Online Published: February 10, 2014

doi:10.5539/jmsr.v3n2p38 URL: http://dx.doi.org/10.5539/jmsr.v3n2p38

\begin{abstract}
Calcium hydrogen phosphate dihydrate is a precursor material of hydroxylapatite; the mineral phase of calcified tissues, and is a biomaterial that is known to show high biocompatibility and resorbability in-vivo. It exhibits anisotropic growth and dissolution behaviors, and quite recently, its conversion kinetics into hydroxylapatite has been reported to alter on coatings with distinct crystal alignments. These imply that biological behaviors of polycrystalline calcium hydrogen phosphate dihydrate are affected by crystal alignment. Meanwhile, an intense magnetic field is a useful tool to induce crystal alignment in various nonmagnetic substances. In this study, the possibility to control crystal alignment of polycrystalline calcium hydrogen phosphate dihydrate using a magnetic field has been investigated. Calcium hydrogen phosphate dihydrate powder having plate-like morphology was synthesized and then its deflocculated suspension was consolidated under a magnetic field of up to 3 T. X-ray diffraction measurements showed that the intensity ratio of (121) against (020) increased on the surface perpendicular to the magnetic field with intensifying the magnetic field strength. Under a 3 T magnetic field, high alignment against (121) plane has been observed which is unfamiliar for calcium hydrogen phosphate dihydrate. The results indicate that a magnetic field successfully induced crystal alignment in polycrystalline calcium hydrogen phosphate dihydrate.
\end{abstract}

Keywords: calcium hydrogen phosphate dihydrate, biomaterial, anisotropy, crystal alignment, magnetic field

\section{Introduction}

Calcium hydrogen phosphate dihydrate (CHPD; $\left.\mathrm{CaHPO}_{4} \cdot 2 \mathrm{H}_{2} \mathrm{O}\right)$, commonly known as the mineral brushite, is a type of calcium phosphate that exhibits higher nucleation rate and lower stability under physiological conditions compared to other calcium phosphate phases (Giocondi et al., 2010; Tamimi et al., 2012). Moreover, CHPD is proposed as one of the possible precursor materials for calcification of hydroxylapatite in natural hard tissues and is proven to be highly biocompatible (Bigi et al., 1988; Vrieze et al., 2012; Wondee et al., 2010; Kumta et al., 2005). The above mentioned properties can trigger pathological mineralization, such as kidney stones, dental caries and plaque, but can also work greatly beneficial in fabricating resorbable biomaterials for tissue engineering (Krambeck et al., 2010; Scudiero et al., 1999; Prasad \& Kamath, 2013; Cheng \& Pritzker, 1983; Kaufman \& Kleinberg, 1973; Kuznetsov et al., 2013).

CHPD crystallizes in a layered structure consisted of alternating layers of calcium and hydrogenphosphate ions and of water molecules stacked along its monoclinic b-axis (Abbona et al., 1993; Schofield et al., 2004). Various properties of CHPD have been reported to be dependent on its crystallographic orientation (anisotropy), most likely due to its anisotropic crystal structure. Both growth and dissolution rates of CHPD were reported to be slowest on the [101] Ia step (Giocondi et al., 2010 ). A larger thermal expansion was seen on the b- and c-axis direction than on a-axis direction (Schofield et al., 2004). Corrosive wear rate on the $\{010\}$ plane was reported to be strongly dependent on the crystallographic orientation of the step (Scudiero et al., 1999). Moreover, conversion kinetics of CHPD into hydroxylapatite has been recently reported to alter on CHPD coatings with distinct crystal alignment (Prasad \& Kamath, 2013). These results imply that crystal alignment affects biological properties of polycrystalline CHPD. 
Meanwhile, application of a magnetic field has been certified as an effective technique to control crystal alignment of nonmagnetic materials like polymers and ceramics with structural anisotropy (Kimura, 2003; Asai et al., 2003; Sakka et al., 2005). For instance, crystal alignment of polycrystalline hydroxylapatite has been induced by imposing a magnetic field during slipcasting, heat substrate method, biomimetic method and even during in-vivo mineralization (Sakka et al., 2008; Inoue et al., 2003; Kaufman \& Kleinberg, 1973; Singh et al., 2006). In all cases, surfaces perpendicular to the magnetic field were aligned against planes perpendicular to c-plane to some extent. A magnetic field induced similar crystal alignment behavior regardless of fabrication techniques, most likely since their principles were all based on the magnetization energy difference expressed in the following equation (Asai et al., 2003).

$$
\Delta \mathrm{U}=\mathrm{U}_{\mathrm{i}-\mathrm{U}_{\mathrm{j}}}: \mathrm{U}_{\mathrm{i}}=-\chi_{\mathrm{i}} \mathrm{B}^{2} /\left\{2 \mu_{0}(1+\chi \mathrm{N})\right\}
$$

Here, the subscript $\mathrm{i}$ or $\mathrm{j}$ indicates the crystallographic orientation of $\mathrm{i}$ - or $\mathrm{j}$-direction, $\chi$ is magnetic susceptibility, $\mu_{0}$ is magnetic permeability in vacuum, $\mathrm{N}$ is the demagnetization factor and $\mathrm{B}$ is the applied magnetic field. Understanding magnetically induced crystal alignment behaviors may thus enable application to various existing fabrication techniques.

In this study, our objective was to find out whether crystal alignment of CHPD can be induced using a magnetic field. Furthermore, we investigated the effect of magnetic field strength and deffloculation methods applied to the casted CHPD suspension.

\section{Method}

\subsection{Materials}

Disodium hydrogen phosphate $\left(\mathrm{Na}_{2} \mathrm{HPO}_{4}\right)$, calcium chloride $\left(\mathrm{CaCl}_{2}\right)$ and plaster $\left(\mathrm{CaSO}_{4}\right)$ were purchased from Kishida Chemical Co., Ltd. A polymeric dispersing agent; Celuna D-305, was provided from Chukyo Yushi Co., LTD. All chemicals were used without further purification.

\subsection{Synthesis of CHPD}

The synthesis of CHPD powder was carried out in a similar manner described elsewhere (Wondee et al., 2010; Kumta et al., 2005; Cheng \& Pritzker, 1983; Kuznetsov et al., 2013; Abbona et al., 1993) with minor changes. In a typical synthesis, clear solutions of $\mathrm{Na}_{2} \mathrm{HPO}_{4}$ and $\mathrm{CaCl}_{2}$ have been prepared by completely dissolving $\mathrm{Na}_{2} \mathrm{HPO}_{4}$ of $3.00 \mathrm{~g}$ and $\mathrm{CaCl}_{2}$ of $1.47 \mathrm{~g}$ into distilled water of $10 \mathrm{~g}$ and $40 \mathrm{~g}$, respectively. Then, approx. $\mathrm{Na}_{2} \mathrm{HPO}_{4}$ solution of $5.5 \mathrm{~g}$ was added dropwise into $\mathrm{CaCl}_{2}$ solution under vigorous stirring and was aged for more than 6 hours at room temperature. The precipitated white powder was filtered, washed with ion-exchanged water and then dried overnight without any external heating. The synthesized powder was then collected and its crystalline phase and morphology were analyzed using X-ray diffraction (XRD, Shimadzu Co. LTD., XRD-6100, $\mathrm{Cu}-\mathrm{K} \alpha$ radiation) and scanning electron microscopy (SEM, Keyence Corporation, VE-7800).

\subsection{Specimen Preparation and Evaluation of Magnetically Induced Crystal Alignment}

Specimens were prepared by the slip casting process. The synthesized powder was suspended in ion-exchanged water and was deflocculated with the help of a polymeric dispersing agent and mechanical milling treatment to obtain a slip. The milling treatment was carried out for an hour using agate mortor. The slip was poured into cylindrical molds with basal planes and surroundings composed of plaster and polypropylene, respectively, and were consolidated under $0,1,2$, and $3 \mathrm{~T}$ magnetic fields generated by a cryocooler cooled superconducting magnet (Sumitomo Heavy Industries., LTD., HF7.5-100VHT-100HT). The dehydration during casting proceeded only from plaster, i.e. the basal plane of the mold. The magnetic field was applied perpendicular to the basal plane of the mold, which is equivalent to the gravitational direction. Also a duplicate experiment was carried out for 0 and $3 \mathrm{~T}$ magnetic fields, however, with additional sonication for 0.33 hours before casting to enhance dispersibility of the CHPD powder in the slip. Crystal alignment of the specimens was investigated by XRD.

\section{Results}

\subsection{Characterization of Synthesized CHPD}

XRD pattern of the synthesized powder is shown in Figure 1. All peaks well matched those of CHPD registered in The International Centre of Diffraction Data (ICDD, JCPDS\#72-0713), meaning that the synthesized powder was single phased CHPD. According to SEM observations shown in Figure 2, the powders were mainly 2-10 $\mu \mathrm{m}$ in size showing a plate-like morphology and were stacked together comprising aggregates. The largest facet of the plate-like CHPD is expected to be consisted of $(0 \mathrm{k} 0)$ planes considering the XRD results and perceptions from previous studies (Abbona et al., 1993; Mandel \& Tas, 2010). 


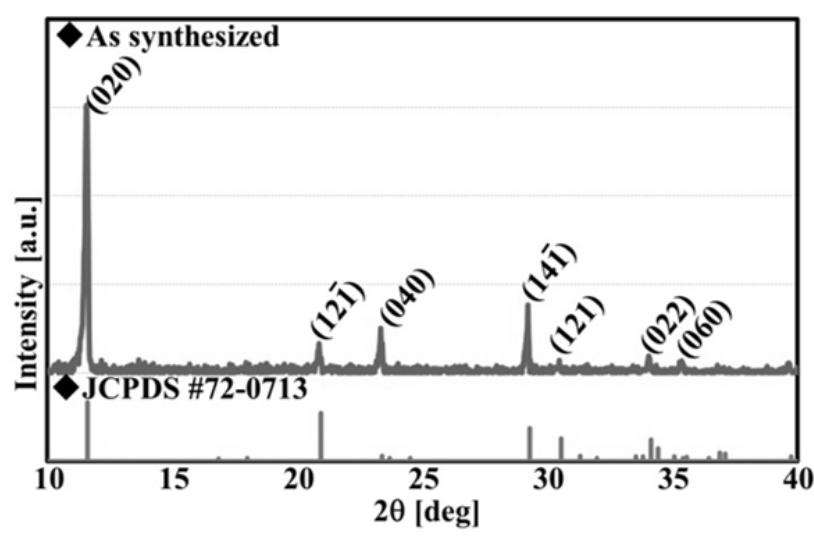

Figure 1. XRD spectrum of synthesized powder

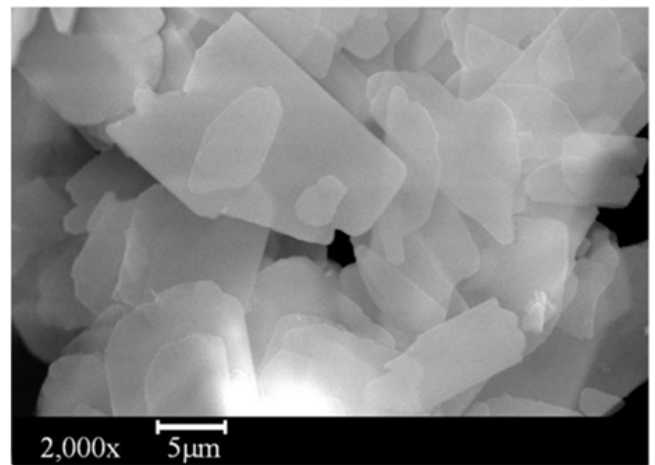

Figure 2. SEM image of synthesized CHPD powder

\subsection{Crystal Alignment of Specimens}

Figure 3 shows the XRD patterns of the specimens consolidated under $0,1,2$, and $3 \mathrm{~T}$ magnetic fields, respectively. The XRD pattern of the specimen consolidated without a magnetic field $(B=0 \mathrm{~T})$ is nearly consistent with that of the synthesized powder showing an intense reflection of (020) plane. Thus, we can say that no crystal alignment was induced by the fabrication method itself. Meanwhile, application of a magnetic field during casting increased relative intensities of (121) and (022); which are planes 67.3 and 69.8 degrees inclined from (020) plane, respectively, in the specimens. A similar trend was also observed in the duplicate experiment carried out with additional sonication as shown in Figure 4. A schematic of the three crystal planes are illustrated in Figure 5. It seems that the crystal is rotating in a direction that the angle between (020) plane of CHPD and magnetic field decreases. These results indicate that the b-axis of CHPD tends to move away from the magnetic field direction and that crystal alignment against (121), which we believe is unfamiliar for CHPD, was successfully induced by applying the magnetic field.

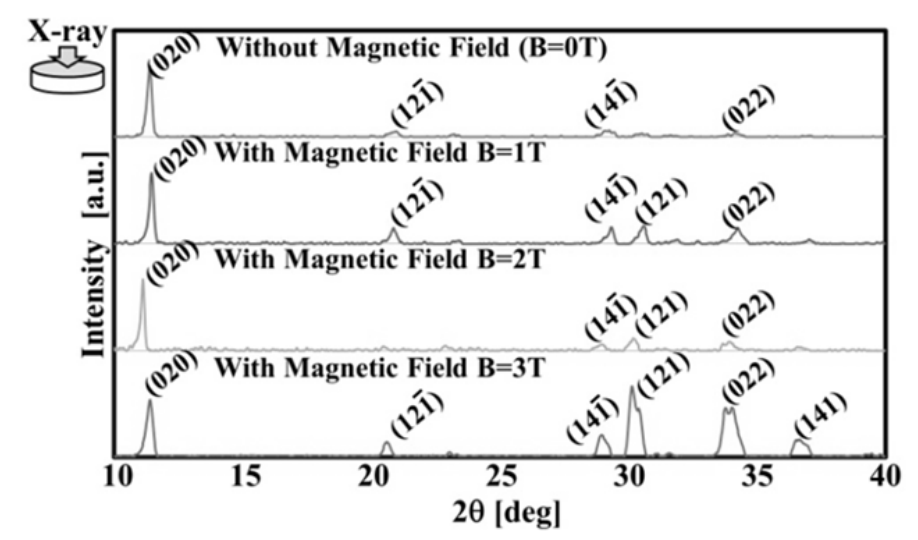

Figure 3. XRD spectra of specimens fabricated with different magnetic field strengths 


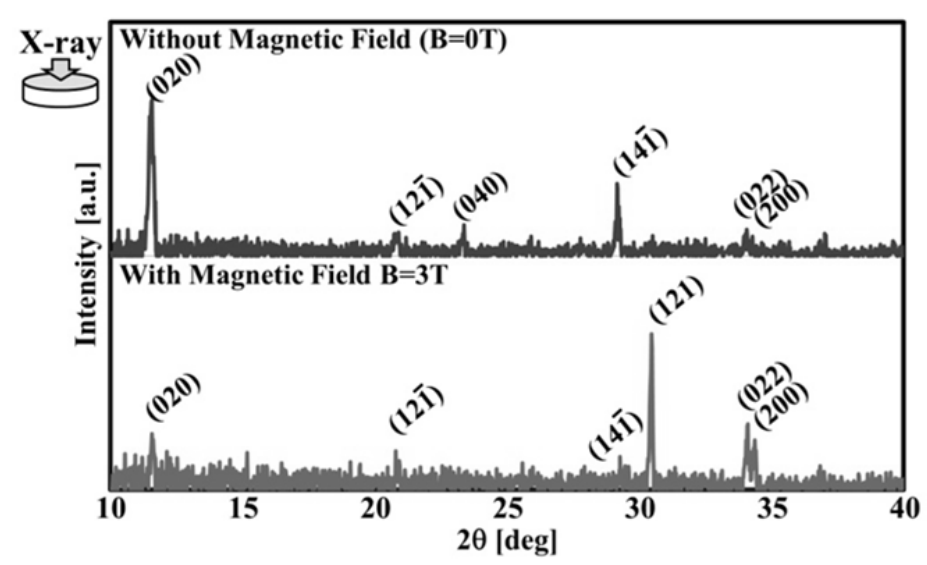

Figure 4. XRD spectra of specimens fabricated with sonication

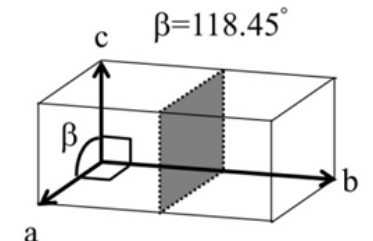

(i) (020) plane

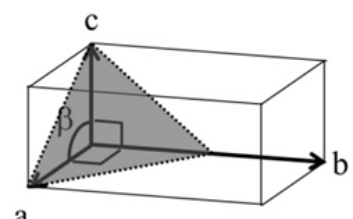

(ii) (121) plane

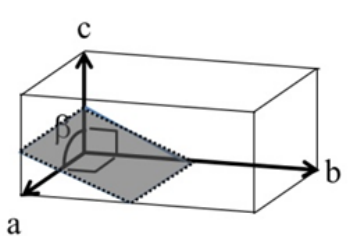

(iii) (022) plane

Figure 5. Schematic view of crystal planes

The effect of magnetic field strength on crystal alignment is examined through transition of $R / R_{0}$ against magnetic field strength, where $R$ is the intensity ratio of (121) to (020) of the specimen and $R_{0}$ is that of the synthesized powder, as is shown in Figure $6 . \mathrm{R} / \mathrm{R}_{0}$ slightly increased up to $2 \mathrm{~T}$ and then drastically increased at 3 $\mathrm{T}$. This seems to indicate that even a weak magnetic field of $1 \mathrm{~T}$ affects alignment of CHPD crystals, however, magnetic field strength equal to or greater than $3 \mathrm{~T}$ was effective to induce crystal alignment of CHPD used in this study.

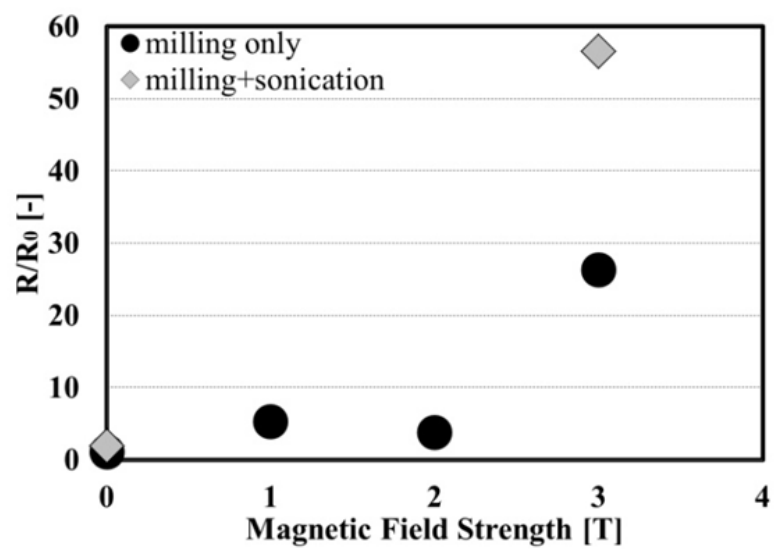

Figure 6. Relation of applied magnetic field strength and alignment against (121)

Also, from Figure 6, it appeared that additional sonication enhances the degree of crystal alignment. This may be explained by the difference in dispersibility of the casted suspension. Aggregation is known to cancel out magnetic anisotropy of single crystals (Sakka et al., 2008), thus this enhancement can be interpreted as a result of higher dispersibility induced by the sonication treatment. Actually, a higher dispersibility has been reported for 
$\alpha$-alumina suspension when it was sonicated than when it was mechanically milled for 2 hours (Novak \& König, 2009). Combination of milling and sonication must have been valid for the process used in this study, since milling shall break down heavy aggregations and sonication shall disgregate weakly cohered particles.

\section{Conclusion}

The possibility to control crystal alignment of polycrystalline CHPD using a magnetic field has been investigated in this study. Deflocculated suspensions of CHPD powder having plate-like morphology was consolidated under a magnetic field of up to $3 \mathrm{~T}$. An increase in the intensity ratio of (121) against (020) on the surface of the specimen perpendicular to the magnetic field was observed by XRD. This indicates that a magnetic field has successfully induced crystal alignment in polycrystalline CHPD. Specimen with high alignment against (121) plane has been obtained which we believe is unfamiliar for CHPD. Also, combination of mechanical milling and sonication was found to valid to modify this process. The finding may be applicable to various existing fabrication methods, and contribute to controlling biological behaviors of biomaterials composed of CHPD.

\section{Acknowledgements}

We express our profound gratitude to Professor Ichino and Assistant Professor Kamimoto for instrumental support during this study.

\section{References}

Abbona, F., Christensson, F., Angela, M. F., \& Madsen, H. E. L. (1993). Crystal habit and growth conditions of brushite, $\mathrm{CaHPO}_{4} \cdot 2 \mathrm{H}_{2} \mathrm{O} . \quad J . \quad$ Crystal Growth, 131, 331-346. http://dx.doi.org/10.1016/0022-0248(93)90183-W

Asai, S., Sassa, K., \& Tahashi, M. (2003). Crystal orientation of non-magnetic materials by imposition of a high magnetic field. Sci. Tech. Adv. Mater., 4, 455-460. http://dx.doi.org/10.1016/j.stam.2003.07.001

Bigi, A., Gazzano, M., Ripamonti, A., \& Roveri, N. (1988). Effect of foreign ions on the conversion of brushite and octacalcium phosphate into hydroxyapatite. J. Inorg. Biochem., 32, 251-257. http://dx.doi.org/10.1016/0162-0134(88)85004-9

Cheng, P. T., \& Pritzker, K. P. H. (1983). Solution Ca/P Ratio Affects Calcium Phosphate Crystal Phases. Calcif. Tissue Int., 35, 596-601. http://dx.doi.org/10.1007/BF02405100

Giocondi, J. L., El-Dasher, B. S., Nancollas, G. H., \& Orme, C. A. (2010). Molecular mechanisms of crystallization impacting calcium phosphate cements. Phil. Trans. R. Soc. A, 368, 1937-1961. http://dx.doi.org/10.1098/rsta.2010.0006

Inoue, K., Sassa, K., Yokogawa, Y., Sakka, Y., Okido, M., \& Asai, S. (2003). Control of Crystal Orientation of Hydroxyapatite by Imposition of a High Magnetic Field. Mater. Trans., 44(6), 1133-1137. http://dx.doi.org/10.2320/matertrans. 44.1133

Kaufman, H. W., \& Kleinberg, I. (1973). X-ray diffraction examination of calcium phosphate in dental plaque. Calcif. Tissue Res., 11(2), 97-104. http://dx.doi.org/10.1007/BF02547292

Kimura, T. (2003). Study on the Effect of Magnetic Fields on Polymeric Materials and Its Application. Polymer Journal, 35(11), 823-843. http://dx.doi.org/10.1295/polymj.35.823

Krambeck, A. E., Handa, S. E., Evan, A. P., \& Lingeman, J. E. (2010). Brushite stone disease as a consequence of lithotripsy? Urol. Res., 38, 293-299. http://dx.doi.org/10.1007/s00240-010-0289-y

Kumta, P. N., Sfeir, C., Lee, D. H., Olton, D., \& Choi, D. (2005). Nanostructured calcium phosphates for biomedical applications: Novel synthesis and characterization. Acta Biomaterialia, 1, 65-83. http://dx.doi.org/10.1016/j.actbio.2004.09.008

Kuznetsov, V. N., Yanovska, A. A., Stanislavov, A. S., Danilchenko, S. N., \& Sukhodub, L. F. (2013). The Study of the Influence of Static Magnetic Field on Brushite Crystallization in the Presence of Magnesium. Proceedings of the International Conference Nanomaterials: Applications and Properties.

Mandel, S., \& Tas, A. C. (2010). Brushite $\left(\mathrm{CaHPO}_{4} \cdot 2 \mathrm{H}_{2} \mathrm{O}\right)$ to octacalcium phosphate $\left(\mathrm{Ca}_{8}\left(\mathrm{HPO}_{4}\right)_{2}\left(\mathrm{PO}_{4}\right)_{4} \cdot 5 \mathrm{H}_{2} \mathrm{O}\right)$ transformation in DMEM solutions at $36.5{ }^{\circ} \mathrm{C}$. Mater. Sci. Eng. C, 30, 245-254. http://dx.doi.org/10.1016/j.msec.2009.10.009

Novak, S., \& König, K. (2009). Fabrication of alumina parts by electrophoretic deposition from ethanol and aqueous suspensions. Ceram. Int., 35, 2823-2829. http://dx.doi.org/ 10.1016/j.ceramint.2009.03.033

Prasad, B. E., \& Kamath, P. V. (2013). Electrodeposition of dicalcium phosphate dihydrate coatings on stainless 
steel substrates. Bull. Mater. Sci., 36(3), 475-481. http://dx.doi.org/10.1007/s12034-013-0468-x

Sakka, Y., \& Suzuki, T. S. (2005). Texture development of Feeble Magnetic Ceramics by Colloidal Process under High Magnetic Field. J. Ceram. Soc. J., 113(1), 26-36. http://dx.doi.org/10.2109/jcersj.113.26

Sakka, Y., Takahashi, K., Suzuki, T. S., Ito, S., \& Matsuda, N. (2008). Texture development of hydroxyapatite ceramics by colloidal processing in a high magnetic field followed by sintering. Mater. Sci. Eng. A, 475, 27-33. http://dx.doi.org/10.1016/j.msea.2006.12.143

Schofield, P. F., Knight, K. S., Houwen, J. A. M., \& Jones, E. V. (2004). The role of hydrogen bonding in the thermal expansion and dehydration of brushite, di-calcium phosphate dehydrate. Phys. Chem. Minerals, 31, 606-624. http://dx.doi.org/10.1007/s00269-004-0419-6

Scudiero, L., Langford, S. C., \& Dickinson, J. T. (1999). Scanning force microscope observations of corrosive wear on single-crystal brushite $\left(\mathrm{CaHPO}_{4} \cdot 2 \mathrm{H}_{2} \mathrm{O}\right)$ in aqueous solution. Tribology Lett., 6, 41-55. http://dx.doi.org/10.1023/A:1019134901387

Singh, P., YashRoy, R. C., \& Hoque, M. (2006). Augmented bone-matrix formation and osteogenesis under magnetic field stimulation in vivo XRD, TEM and SEM investigations. Ind. J. Biochem. Biophys., 43, $167-172$.

Tamimi, F., Nihouannen, D. L., Eimar, H., Sheikh, Z., Komarova, S., \& Barralet, J. (2012). The effect of autoclaving on the physical and biological properties of dicalcium phosphate dihydrate bioceramics: Brushite vs. monetite. Acta Biomaterialia, 8, 3161-3169. http://dx.doi.org/10.1016/j.actbio.2012.04.025

Vrieze, E., Heijnen, L., Metz, J. R., \& Flik, G. (2012). Evidence for a hydroxyapatite precursor in regenerating cyprinid scales. J. Appl. Ichthyol., 28, 388-392. http://dx.doi.org/10.1111/j.1439-0426.2012.01989.x

Wondee, B., Danvirutai, C., \& Srithanratana, T. (2010). Simple synthesis, FTIR/FT Raman Spectroscopic studies and non-isothermal dehydration kinetics of $\mathrm{CaHPO}_{4} \cdot 2 \mathrm{H}_{2} \mathrm{O}$. Proceedings of Pure and Applied Chemistry International Conference.

Xu, C. Y., Xu, X. L., Gao, F., Chu, F. X., Wang, Q., \& Guo, Q. N. (2013). The Crystal Orientation of Hydroxyapatite Coatings Affected by the Magnetic Fields on Magnesium Alloy. Appl. Mech. Mater., 395-396, 751-754. http://dx.doi.org/10.4028/www.scientific.net/AMM.395-396.751

\section{Copyrights}

Copyright for this article is retained by the author(s), with first publication rights granted to the journal.

This is an open-access article distributed under the terms and conditions of the Creative Commons Attribution license (http://creativecommons.org/licenses/by/3.0/). 